\title{
Risk preference and feedback
}

\author{
ORFELIO G. LEÓN \\ Universidad Autonoma de Madrid, Madrid, Spain \\ and \\ LOLA L. LOPES \\ University of Wisconsin, Madison, Wisconsin
}

\begin{abstract}
Subjects' preferences for a set of multi-outcome lotteries were assessed, and then subjects were exposed to a feedback period in which they played the lotteries and received information concerning outcomes. Afterward, preferences were reassessed. Most subjects' preferences were risk averse in the prefeedback assessment, regardless of whether they were making single decisions (short-run condition) or choices for repeated plays (long-run condition), but long-run subjects were less risk averse than short-run subjects. In the postfeedback assessment, about half of the subjects in each condition became risk seeking and the other half maintained their risk-averse preferences. There were, however, differences between short-run and long-run subjects in the postfeedback pattern of risk seeking.
\end{abstract}

Information about the consequences of decisions serves as important input for later decisions. Several previous studies have investigated how feedback affects gamble preferences when subjects are either winning or losing (Edwards, 1954; Greenberg \& Weiner, 1966; Leopard, 1978; McGlothin, 1956; Morgan, 1983). The most general conclusion from these studies is that people prefer riskier gambles when they are losing. However, these studies do not differentiate between the impact of experience per se and the outcomes of experience, nor do they differentiate between baseline preferences and preferences in the first trial block.

Two more recent studies remedied some of these deficiencies. León and Gambara (1986) established a baseline measure of gamble preferences for each subject before any feedback was given. Then experience with the gambles was provided and preferences were reassessed. The main result was that $69 \%$ of the subjects changed their preferences after feedback. However, the characteristics of the gambles made interpretation of the changes difficult.

León (in press) followed a similar procedure. His stimuli were two pairs of gambles that reliably produce the certainty effect. In these pairs, most subjects prefer a sure thing to a gamble with higher expected value, but prefer the gamble when both it and the sure thing have their probabilities reduced by the same linear transformation. The result was that all subjects initially showed the certainty effect on both pairs of problems, but after playing the gambles several times, $65 \%$ of the subjects for one pair and $83 \%$ of the subjects for the other pair

This research was facilitated by Grant VB-864009 from the USA-Spanish Joint Committee to the first author and Office of Naval Research Contract N00014-84K-0065, R\&T 4425079, to the second author. Requests for reprints should be sent to Orfelio León, Department of Psychology, Universidad Autonoma de Madrid, 28049 Madrid, Spain. failed to demonstrate the certainty effect. Instead, some subjects always chose the more sure option, whereas others always chose the gamble with the smaller probability but greater expected value.

In León's (in press) study, people's risk attitudes became more consistent after feedback, but that is almost guaranteed for these particular gambles. The purpose of the present study was to determine whether feedback produces systematic changes in people's risk attitudes, by using a more continuous stimulus set and a more sensitive task.

The stimuli were a set of six lotteries that produce a systematic pattern of risk aversion in most subjects (Lopes, 1984, 1987). We measured subjects' preferences among the lotteries once before and once after a series of choice trials with feedback. The main comparison was between pre- and postfeedback preference patterns.

A second manipulation concerns the difference between preferences expressed for single trials (short run) and preferences expressed for multiple trials (long run). This variable is of interest because both theoretical arguments (Lopes, 1981) and empirical study (Keren \& Wagenaar, 1987; Montgomery \& Adelbratt, 1982) suggest that unique gambles and repeated gambles are not perceived or processed in the same way.

\section{METHOD}

\section{Subjects}

The subjects were 60 students taking an introductory psychology course at University of Wisconsin. The subjects received extra credit to be applied to their course grades.

\section{Stimuli}

The stimuli were a set of six multi-outcome lotteries (reproduced in Lopes, 1987), each having an expected value of approximately $\$ 100$. The riskless lottery (RL) is a positively skewed lottery with a minimum prize of $\$ 70$ and a maximum prize of $\$ 200$. The short shot (SS) is a 
negatively skewed reflection of the riskless lottery with a $\$ 0$ minimum and a $\$ 130$ maximum. The peaked (PK), rectangular $(\mathrm{RC})$, and bimodal (BM) lotteries are all symmetrical with a \$0 minimum and $\$ 200$ maximum. The long shot (LS) is a high-variance positively skewed lottery with a $\$ 0$ minimum and a $\$ 439$ maximum. Risk-averse subjects typically prefer these lotteries in the order RL $>$ SS $\geq$ PK $>$ RC $>$ BM > LS (Lopes, 1984; Schneider \& Lopes, 1986).

\section{Design and Procedure}

The design was a 6 (lotteries) $\times 2$ (pre- vs. postfeedback assessment) $\times 2$ (short-run vs. long-run task) factorial. Lotteries and feedback were varied within subjects and task was varied between subjects. The dependent variable was the number of times the subjects chose each of the lotteries in a complete pair-comparison design.

Prefeedback. The subjects were run individually in a computerized laboratory. At the beginning of the session, the subjects were given a booklet in which lottery pairs were printed with one pair per page. The subjects indicated their preferences on a separate response sheet. Shortrun subjects were instructed to indicate which of the lotteries they would choose if they were allowed to play either of the lotteries once. Longrun subjects were instructed to indicate which of the lotteries they would choose if they were allowed to play either of the lotteries 20 times with independent sampling for each of the draws.

Feedback. After the subjects had expressed their initial preferences (approximately $10 \mathrm{~min}$ ), the feedback phase of the experiment was introduced. Lotteries were displayed on a poster positioned close to the screen. Each was labeled with a letter (A though F). Choice pairs were indicated by their letter codes on an Apple II+ computer. The subjects responded by pressing the keyboard letter corresponding to the lottery they preferred in each pair.

In the short-run condition, each pair of lotteries was presented 10 different times, making 150 choices and 150 feedback trials. In the long-run condition, each lottery pair was presented twice, but with each choice applying to a block of 20 draws from the preferred lottery. This made 30 choices and 600 feedback trials. These particular values were chosen so that there would be about $25 \mathrm{~min}$ of feedback for each group.

Lottery draws were presented to individual subjects by means of a random number routine running on the computer. The same procedure was used for both conditions, except that, after each choice, short-run subjects selected a single random number whereas long-run subjects selected 20 random numbers, receiving feedback separately for each of the 20 draws. Between successive draws, the screen was cleared, so that no distributional information was available to the subjects other than what they remembered about previous outcomes.

In order to increase the subjects' involvement in the feedback task, the computer kept track of the subjects' cumulative outcomes (but did not display these during the actual experiment). A prize of $\$ 10$ was offered to the subject in each condition who received the largest total outcome during the feedback period.

Postfeedback. After the feedback trials, the booklets from the prefeedback task were returned to the subjects, and they again indicated their preferences according to the instructions used in the prefeedback task. This took about $5 \mathrm{~min}$. Following this, the subjects were debriefed and informed of their scores in the feedack trials. Prizes were awarded to the winners after all the subjects had been run.

\section{RESULTS}

The data for the experiment are the number of times that a subject chose each lottery in the pre- and postfeedback tasks. Since each lottery was paired once with each of the others, the maximum number of choices per lottery was five and the minimum was zero.

Table 1 shows the data, averaged over subjects. Lotteries are listed in the order in which they are typically preferred by risk-averse subjects. As is obvious, there were reliable differences among the lotteries $[F(5,290)$ $=13.22, p<.001]$. This overall tendency was affected
Table 1

Mean Preference Scores for Lotteries Across Conditions

\begin{tabular}{lccccc}
\hline & \multicolumn{4}{c}{ Conditions } \\
\cline { 2 - 3 } & \multicolumn{2}{c}{ Short Run } & & \multicolumn{2}{c}{ Long Run } \\
\cline { 2 - 3 } \cline { 5 - 6 } Lottery & Prefeedback & Postfeedback & & Prefeedback & Postfeedback \\
\hline Riskless & 3.27 & 3.40 & & 3.10 & 2.37 \\
Short Shot & 3.17 & 2.23 & & 2.77 & 2.80 \\
Peaked & 3.20 & 2.43 & & 3.07 & 2.97 \\
Rectangular & 2.77 & 2.43 & & 2.73 & 2.83 \\
Bimodal & 1.67 & 2.20 & & 1.90 & 2.20 \\
Long Shot & .93 & 2.30 & & 1.43 & 1.83 \\
\hline
\end{tabular}

Note-Maximum score $=5$, minimum $=0$.

by feedback, however, as evidenced by a strong two-way interaction between lottery and feedback $[F(5,290)=$ $5.12, p<.001]$, and a weaker but still significant threeway interaction between lottery, feedback, and task $[F(5,290)=2.97, p<.025]$.

Before feedback, subjects in both groups tended to be risk averse (i.e., the mean preference function decreases from RL to LS), although the function for short-run subjects is steeper than that for long-run subjects $\left[F_{\text {linear }}(1,29)\right.$ $=60.49$ and 22.90 , respectively, both $p \mathrm{~s}<.001]$. This signifies greater risk aversion for short-run subjects. After feedback, the mean preference function is flatter overall $[F(5,290)=2.10$, n.s. $]$, but it is not identical for the two groups $[F(5,290)=2.23, p<.05]$.

In a pair-choice task, flat preference functions indicate that individual subjects were unsystematic in their choices or that the preference patterns of individual subjects cancelled one another out. To determine which occurred in the present case, we reanalyzed the data, with subjects classified into risk-averse (RA) and risk-seeking (RS) groups. For convenience, we based our index of risk attitude on the number of times the bimodal and long shot lotteries were selected (out of 10 possible). Subjects with $\mathrm{BM}+\mathrm{LS} \leq 4$ were classified as RA, and subjects with $\mathrm{BM}+\mathrm{LS} \geq 5$ were classified as $\mathrm{RS}$.

Figure 1 gives the data for the prefeedback RA subjects $(n=49)$. (The data for prefeedback RS subjects were not analyzed further because there were so few of them.) The upper and lower panels distinguish subjects on the basis of postfeedback risk attitude. In the short-run condition, there were 15 subjects (upper left) whose pre- and postfeedback preferences were essentially identical (i.e., risk averse) $[F(5,70)=2.00$, n.s. $]$. For another 12 subjects (lower left), however, there was a dramatic shift to risk seeking after feedback $[F(5,55)=11.67, p<.001]$. The U shape in the postfeedback data for these subjects is typical of the preference patterns of naturally riskseeking subjects operating under neutral conditions (Schneider \& Lopes, 1986) and also of naturally riskaverse subjects operating under conditions that foster high aspiration levels (Lopes \& Casey, 1987; Lopes \& Schneider, 1987).

The results in the long-run condition were similar. There were 14 uniformly RA subjects (upper right) whose pre- and postfeedback preferences were essentially identical $[F(5,65)=1.57$, n.s.], and 8 subjects (lower right) 

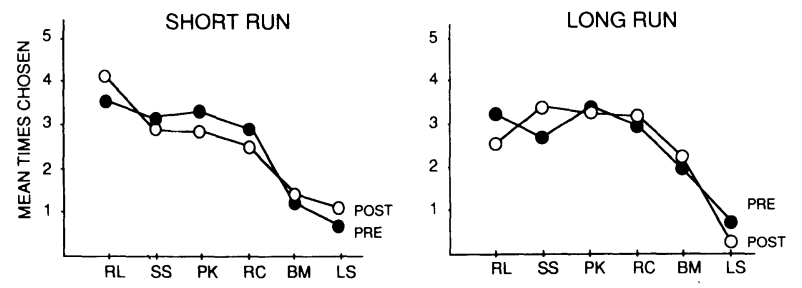

POSTFEEDBACK RISK AVERSE
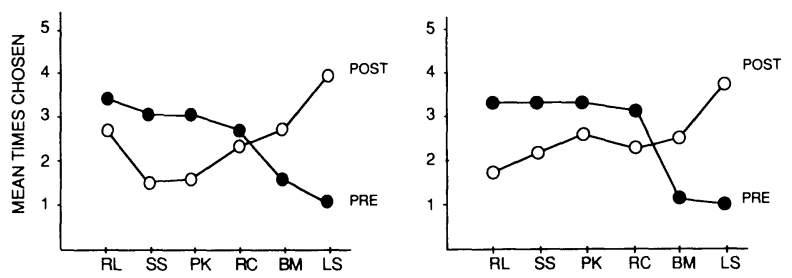

POSTFEEDBACK RISK SEEKING

Figure 1. Pre- and postfeedback preferences, with subjects classified as risk averse (upper panels) and risk seeking (lower panels) for the short-run (left panels) and long-run (right panels) conditions. $\mathrm{RL}=$ riskless lottery, $\mathrm{SS}=$ short shot, $\mathrm{PK}=$ peaked lottery, $\mathrm{RC}=$ rectangular lottery, $\mathrm{BM}=$ bimodal lottery, $\mathrm{LS}=$ long shot.

for whom there was a clear shift to risk seeking after feedback $[F(5,35)=9.35, p<.001]$. In this case, however, there was no $U$ pattern.

\section{DISCUSSION}

The main result of the present experiment was that subjects' experience with the outcomes of lotteries increased between-subject differences in risk attitude. In both task conditions, most of our subjects $(82 \%)$ displayed risk aversion before feedback. After feedback, however, some subjects maintained their risk aversion while others became risk seeking. This polarizing effect of feedback is similar to that found previously by León (in press).

Why some people change preferences and others do not is not clear, but the result appears to be quite general. Two previous studies (Lopes \& Casey, 1987; Lopes \& Schneider, 1987) that used these same stimuli attempted to shift subjects toward risk seeking by manipulating an external goal. In both cases, many subjects were unresponsive to global manipulations, although most responded if the need for risk taking was immediate and concrete. In the case of feedback, León and Gambara (1986) also found that a sizable subgroup of subjects maintained prefeedback preference patterns.

There are at least two reasons why subjects may maintain their preferences. One is that they may be uninvolved and behave superficially. Another is that feedback may confirm the wisdom of previous preferences (i.e., a person making risk-averse choices will win something on most trials). The present data do not distinguish these possibilities, although observation of the subjects did not suggest that they were uninvolved with the task.

The motives of subjects who become risk seeking are also ambiguous. One possibility is that they switch preferences because they are bored and are seeking variety. Another is that they are doing poorly and become risk seeking in order to catch up. A third is that their postfeedback responses reflect the demands of the payoff structure of the feedback task. And a fourth is that feedback causes them to change their views on the relative merits of different lotteries.

In the present case, the first possibility seems unlikely since variety seeking would have produced erratic choices and not a clear pattern of risk seeking. The second possibility also seems unlikely since there were no reliable differences between the cumulative scores of risk-averse and risk-seeking subjects in the feedback task. But the other two possibilities both may have operated if subjects took risks in the feedback trials in order to try for the prize and discovered, in so doing, that the risky lotteries were not so bad after all.

A secondary result concerns the task manipulation. We found only two differences between long-run and short-run subjects. The first is that fewer subjects were risk averse in the long-run than in the shortrun condition ( $73 \%$ vs. $90 \%$ ). Similar reductions in risk aversion in long-run situations have been observed previously (Keren \& Wagenaar, 1987; Montgomery \& Adelbratt, 1982), although the effect appears to be somewhat smaller in the present case. This probably reflects the fact that our stimuli had equal expected values, whereas the riskier stimuli in the other experiments had higher expecterd values.

The second difference involves the responses of postfeedback RS subjects to the riskless lottery. In the short-run condition, preference for the maximally safe riskless lottery remained fairly high for postfeedback RS subjects, despite the general shift to risk seeking. In the longrun condition, however, postfeedback RS subjects did not maintain residual preference for the riskless lottery.

Preference for the riskless lottery among risk seekers is typical of what has been found previously (Lopes, 1987; Lopes \& Casey, 1987; Lopes \& Schneider, 1987; Schneider \& Lopes, 1986). Protocols given by subjects at the point of choice suggest that this lottery is universally attractive because it offers both security and potential. That is, it is at least as good as the short shot and peaked lotteries in terms of best-case outcomes and it offers a clearly superior worst-case guarantee of $\$ 70$. For subjects making choices on a trial-by-trial basis, this combination seems to have great appeal.

In the case of choices that apply to an entire block of trials, security appears to diminish in importance. This is not surprising, since subjects have been shown (Montgomery \& Adelbratt, 1982) to have a reasonably good understanding that with multiple plays, poor outcomes on some trials will probably be compensated by good outcomes on other trials. This reduces security differences among lotteries. But potential differences remain relevant even for long-run choices. Since 30 subjects competed for each prize in the feedback task, it was highly likely that the best overall score would be obtained by someone who pursued risky choices (i.e., choices like the BM and LS lotteries that have low security but high potential).

In summary, our results suggest that experience with lotteries can affect people's preference patterns in both short-run and long-run contexts. The exact reasons for these changes are unclear, however, and further research is needed to clarify them.

\section{REFERENCES}

EDWARDS, W. (1954). Variance preferences in gambling. American Journal of Psychology, 67, 441-452.

GreenberG, M. G., \& Weiner, B. (1966). Effects of reinforcement history upon risk-taking behavior. Journal of Experimental Psychology, 71, 587-592.

Keren, G., \& WagenaAR, W. A. (1987). Violation of utility theory in unique and repeated gambles. Journal of Experimental Psychology: Learning, Memory, \& Cognition, 13, 387-391.

LEón, O. G. (in press). Influencia de la retroalimentación en el efecto de certidumbre. Revista de Psicologia General y Aplicada.

León, O. G., \& Gambara, H. (1986). Relevancia de la valoración de las consecuencias en la toma de decisiones. Revista de Psicologia General y Aplicada, 40, 1079-1096.

LEOPARD, A. (1978). Risk preferences in consecutive gambling. Journal of Experimental Psychology: Human Perception \& Performance, 4, 521-528.

LOPES, L. L. (1981). Decision making in the short run. Journal of Experimental Psychology: Human Learning \& Memory, 7, 377-385.

LOPES, L. L. (1984). Risk and distributional inequality. Journal of Experimental Psychology: Human Perception \& Performance, 10, 465-485.

LOPES, L. L. (1987). Between hope and fear: The psychology of risk. Advances in Experimental Social Psychology, 20, 255-295.

LOPES, L. L., \& CASEY, J. T. (1987). Tactical and strategic responsiveness in a competitive risk-taking game (Tech. Rep. No. WHIPP 
28). Wisconsin Human Information Processing Program, University of Wisconsin, Madison.

LOPES, L. L., \& SCHNEIDER, S. L. (1987). Risk preference and aspiration level (Tech. Rep. No. WHIPP 27). Wisconsin Human Information Processing Program, University of Wisconsin, Madison.

McGlothin, W. H. (1956). Stability of choices among uncertain alternatives. American Journal of Psychology, 69, 604-615.

Montgomery, H., \& AdelbratT, T. (1982). Gambling decisions and information about expected value. Organizational Behavior \& $\mathrm{Hu}$ man Performance, 29, 29-57.
Morgan, R. L. (1983). Risk preference as a function of the number of wins and the amount won. American Journal of Psychology, 96, 469-475.

SCHNEIDER, S. L., \& LoPES, L. L. (1986). Reflection in preferences under risk: Who and when may sugest why. Journal of Experimental Psychology: Human Perception \& Performance, 12, 535-548.

(Manuscript received for publication November 9, 1987.) 